\title{
Exogenous regulation of biological productivity of fenugreek
}

\author{
Olga M. Savchenko* and Firdaus M. Khazieva \\ All-Russian Scientific Research Institute of Medicinal and Aromatic Plants, 117216 Moscow, Russia
}

\begin{abstract}
In the article the results of the effect on Trigonella foenum-graecum L. productivity by organic fertilizers EcoFus and Siliplant and presowing inoculation of seeds with the Rizotorphyn are presented. We investigated effect of organic-mineral fertilizers "EcoFus" and "Siliplant" and presowing inoculation by "Rhizotorphyn". "EcoFus" and "Siliplant" increase herb yield by 24.8 and $18.8 \%$ compare to control. "Rhizotorphyn" increasing yield of seeds production by $32.1 \%$ compared to control. For the first time we present the data of the study devoted to the effect of foliar treatments with micronutrients and presowing seed inoculation on the quantitative content of flavonoids in fenugreek seeds. The highest flavonoid content was found in seeds subjected to foliar treatments with a binary mixture of "EcoFus + Siliplant" (1.59\%). Work is performed under the topic of the research project No. 0576-2019-0007.
\end{abstract}

\section{Introduction}

Fenugreek (Trigonella foenum-graecum L.) is an annual herbaceous plant, well known in culture since ancient times as valuable forage and medicinal plants.

The fenugreek (Trigonella) genus of the legume family (Fabaceae) consists of 129 species in the world flora, of which 44 are perennial and 85 are annual. On the territory of the Russian Federation grow about 50 species of fenugreek (perennial and annual) [1].

Fenugreek grows naturally in Western Asia, Turkey, Iraq and Iran, spreading to the Himalayas.

It is used for green fodder, hay and green fertilizer. Seeds are used for concentrates, as well as in folk medicine, veterinary medicine and technology. In its pure form fenugreek is not recommended for use. Young shoots are used as a salad, seeds - for cereals, flour. In the southern regions of Russia it is cultivated in busy pairs (for early feed, for green fertilizer) and as stubble [1].

It positively responds to moisture and fertilizers. To soils it is not demanding, unsuitable only to heavy, floating, acidic, waterlogged soil. Many of its ecotypes and geographical forms are not affected by diseases and pests [1].

Fenugreek is a drought-resistant plant, characterized as plastic to growing conditions. Therefore, some of its forms and biotypes can be cultivated up to $60^{\circ}$ North latitude. Shoots appear in 7-8 days after germination of seeds, with a lack of moisture in the soil - in 15-18 days. The plant has a tap root. Stem erect, slightly branched, round, hairy, green, length $25-60 \mathrm{~cm}$. Leaves are trifoliate and short. Leaflets are back-ovate or broadly lanceolate, toothed, glabrous, $2-4 \mathrm{~cm}$ long. The corolla is almost twice as long as the calyx. The fruit is a bean, somewhat curved, glabrous, 6-16 cm long, brown after ripening. Seeds are greenish and yellowish, 4-6 mm long. Weight of 1000 seeds is $14-16 \mathrm{~g}$. The whole plant has an intense odor. [1, 2].

Mature fenugreek seeds contain up to $1.34 \%$ of the amount of steroid saponins (diosgenin, tigonin, yamogenin) and they are used in official medicine in 8 countries [1-3].

Trigonella foenum-graecum $\mathrm{L}$. is well known due to pharmacology advantages: antidiabetic, antioxidant, hypocholesterolemic, anti-tumor, anti-inflammatory, anti-carcinogenic, antipyretic, immunomodulating and anti-tumor. Fenugreek has a tonic effect [4-6].

Polyphenolic flavonoids, which are characterized by hypoglycemic, hypocholesterolemic, hypotriglyceridemic and antiperoxidative properties [7], steroidal saponins exhibiting anti-inflammatory action on the uterus and lactation-stimulating properties [8, 9], such as anisanabarides, were identified and isolated in Trigonella foenum-graecum $\mathrm{L}$ seeds $[8,9]$ have antidiabetic effects [10], the amino acid 4hydroxyisoleucine has insulin-mimetic properties [11].

Fenugreek was conducted at the all-Union research Institute of medicinal and aromatic plants (VILAR, Moscow region), in the Crimean, North Caucasus (preserved branch VILAR) and Ukrainian, the Przheval'skaya zonal experimental stations of VILAR.

All these data confirm the need to continue the study of fenugreek as a source of raw materials for the production of diosgenin. In VILAR has been initiated to restore fenugreek as promising medicinal crops.

In 1980-s medicine "Pasenin" being analog "Polisponin" and "Tribusponin" was developed in Russian State Medicinal and Aromatic Plant research Institute. The "Pasenin" was developed from Trigonella foenum-graecum L. seeds. [12].

Fenugreek hay can be used as a forage plant (due to the presence of protein green mass and hay have high

Corresponding author: swamprat@ rambler.ru 
nutritional properties), and is a good precursor for all vegetable plants.

Research purpose - the studies of non-root treatments effect of micro-fertilizers and presowing inoculation of seeds on yield and flavonoid content in Trigonella foenum-graecum L. seeds.

\section{Materials and methods}

\subsection{Characteristics of the place of the experiment}

The studies were conducted in 2017-2019 on the experimental field of the Department of Agrobiology and Breeding according to the methods adopted for experiments with medicinal plants [13].

The soil of the site is heavy loamy: humus (by Tyurin) $-2.23 \%$, the mass fraction of nitrogen nitrates $<2.80$ million $^{-1}$, the mass fraction of phosphorus compounds (by Kirsanov) $\mathrm{P}_{2} \mathrm{O}_{5}-386.28$ million $^{-1}$, the amount of absorbed bases (by Cappen) - $6.3 \mathrm{mmol} /$ $100 \mathrm{~g}$, salt pH-5.15.

Allocation of plots was randomized. Repeat 4-fold, the square of the each experimental plot was $24 \mathrm{~m}^{2}$.

\subsection{Characteristics of weather conditions during the experiment}

Unstable weather conditions have a negative impact on yields and contribute to the deterioration of the quality of the products. Under these conditions, there is a decrease in plant resistance to stress factors and the inability to obtain the potential productivity of cultivated varieties and populations.

The temperature in the growing seasons of 2017-2019 varied within 3-5 ${ }^{\circ} \mathrm{C}$. In 2017, the temperature during the growing season was on average below the norm by $1.3-3.4 \mathrm{C}$.

In 2018, during the flowering phase and the beginning of fruiting, the air temperature was relatively low and amounted to $16.2-17.3^{\circ} \mathrm{C}$. Precipitation fell in the amount of $60 \mathrm{~mm}$. in the phase of seed ripening (July), the temperature increased (to $20.5^{\circ} \mathrm{C}$ ), precipitation fell $93 \mathrm{~mm}$. Weather conditions in 2019 at the beginning of seed ripening deviated from the norm by $-2.4^{\circ}[13]$.

\subsection{Micronutrients and inoculants}

In order to increase productivity, we used a binary mixture of organic fertilizer "EcoFus" $(5 \mathrm{ml} / \mathrm{L})$ and "Siliplant" microfertilizers $(1 \mathrm{ml} / \mathrm{L})$, which have proven themselves in medicinal plants $[15,16]$.

"Siliplant" is a microfertilizer with a high content of silicium (6-7 \%) in an accessible form for plants. Silicium, which is a part of "Siliplant", activates synthesis of auxins necessary for root system growth. The solution was applied at a concentration of $1 \mathrm{ml} / \mathrm{L}$. $[15,16]$.
"EcoFus" - organic-mineral fertilizer based on fucus algae, contains physiologically active substances possessing immunostimulating, antiviral, antibacterial and fungicidal action. The solution was applied at a concentration of $5 \mathrm{ml} / \mathrm{L}$. Consumption 300-400 1/hectare.

The inoculation of seeds was carried out with the biological product "Rhizotorphyn" (200 g/hectare). "Rhizotorphyn" (strains of nodule bacteria of the genera: Bradyrhizobium, Rhizobium, Sinorhizobium, Mesorhizobium), highly concentrated inoculants with increased biological efficiency based on gamma sterile peat. $1 \mathrm{~g}$ contains at least 2.5 billion Rhizobia. Inoculants have increased nodulation ability of the root system of legumes. As a result of the using of the inoculant, nodulation form on the roots which fix molecular nitrogen $\left(\mathrm{N}_{2}\right)$ from the air and convert it into $\mathrm{NH}_{4}+$ form which accessible for plants. This process allows reducing or abandoning mineral fertilizers introduced into the soil without reducing yield, increases the yield of plants and their resistance to adverse environmental factors [17-19].

The biological product was developed by the Russian State Research Institute of Agricultural Microbiology.

\subsection{Quantitative analysis of flavonoids}

Quantitative analysis of flavonoids in the seeds of fenugreek we have developed methodology based on differential spectrophotometry on a LAMBDA-950 spectrophotometer using a technique for determining flavonoids in combination with Aluminum chloride in the range of 385-460 $\mathrm{nm}$. For quantitation of flavonoids in raw we have developed methodology based on bacteria's ability to form colored complex of $\mathrm{C}_{2} \mathrm{H}_{5} \mathrm{OH}$ and $\mathrm{AlCl}_{3}$ what causes a bathochromic shift of the longwavelength absorption band and at the same time gives the main absorption maximum at a wavelength of $393 \pm$ $2 \mathrm{~nm}$ [20-22].

The extract was left to soak for 24 hours and then the extraction was carried out in a boiling water bath for 30 minutes twice. For develop methods for the quantitative determination of the sum of flavonoids, a reaction with an alcoholic solution of Aluminum chloride was used.

In order to develop the manual we determinate optimal conditions for extractions: ethanol $70 \%$, as extracting. Ratio raw / extracting 1:50. Sum of flavonoids measured in conversion with Apigenin using standard solution of Apigenin CAS№520-36-5 in $95 \%$ ethanol.

The degree of flavonoid content $(\%)$ was calculated by formula:

$$
\mathrm{X}=\frac{\mathrm{A} \cdot \mathrm{m}_{0} \cdot 100 \cdot 100}{\mathrm{~A}_{0} \cdot \mathrm{m} \cdot(100-\mathrm{W})}
$$

$\mathrm{X}$ - flavonoid content conversioned to Apigenin

A - optic density of test solution

$\mathrm{A}_{0}$ - optic density of standard solution ;

$\mathrm{m}$ - raw mass, gramm

$\mathrm{m}_{0}$ - mass standard solution ruthin, gramm;

$\mathrm{W}$ - mass loss on drying of raw materials

Concentrations of Apigenin and Aluminium chloride from 0,0002 to $0,0020 \%$ of are match to meanings of optic density from 0,1 to $1,0 \%$.

This dependence is described by linear equation: 


$$
Y=0.4306 \times X+0.0002
$$

Mean of coefficient of absorption of Apigenin and Aluminium chloride complex is 491 with relative error $3 \%$.

\section{Results and discussions}

In 2017-2019 years sowing of Trigonella foenumgraecum $\mathrm{L}$ was carried out in the first ten days of May in a wide-row method (row spacing $60 \mathrm{~cm}$ ). The sowing rate is $6 \mathrm{~kg} / \mathrm{ha}$, the seed placement depth is $3 \mathrm{~cm}$. The predecessors are black steam. After 7-10 days, seedlings appeared. The field germination of seeds in all variants was $94 \%$ after 20-30 days from the plants began to branch. In the last decade of June, mass budding of plants was observed. In the phase of the onset of seed ripening, the height of the plants had been $39-43 \mathrm{~cm}$ was not increased further.

The length of the growing season of fenugreek plants after treatment by micronutrients was lengthened. From germination to full maturation of seeds in the control variant was 74 days. The time from germination to harvesting of fenugreek plants after treatment by micronutrients was $77-80$ days. The time from germination to harvesting in control variant was 85-95 days. The main phenological phases took of the fenugreek plants, after the influence of non-root treatments with a binary mixture of "EcoFus + Siliplant" take the place on 2-4 days earlier than the plants from the control site.

Foliar treatments and seed inoculation also had a noticeable effect on the intensity of the color of fenugreek leaves and stems. Plants in the variant "EcoFus + Siliplant" were characterized by intensive growth, dark green color of leaves (Fig. 1).

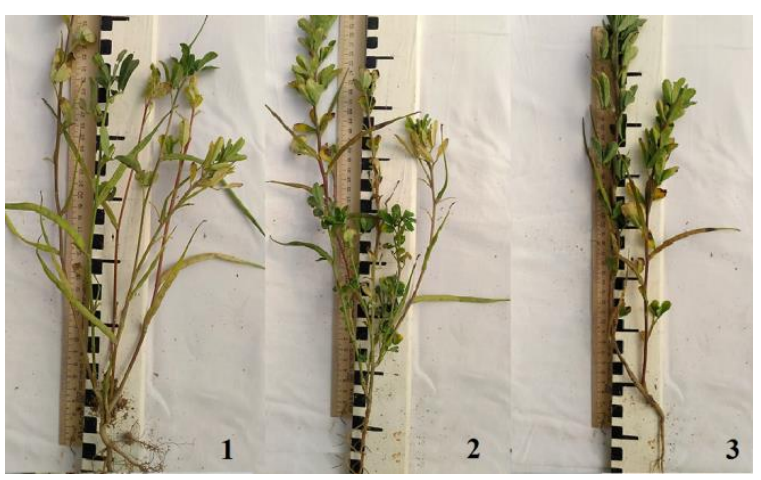

Fig. 1. Plant of fenugreek variants of foliar treatment by: 1 - Presowing inoculation of fenugreek by "Rhizotorphyn";

2 - Foliar treatment by a mixture "EcoFus + Siliplant";

3 - Control

As it is shown in figure 1, seed inoculation significantly stimulates the development of the symbiotic apparatus. The plants of fenugreek have a more branched root system, therefore, get more nutrition.

Foliar treatment by a mixture of organic fertilizer "EcoFus" with microfertilizer "Siliplant" increased plant growth. In 20 days the height of the plants exceeded the control by $7.0 \%$, harvesting (third decade of August) by $4.3 \%$ (Table 1). "Rhizotorphyn" increased plant height by $7.8 \%$ in budding phase compare to control and by $4.8 \%$ in harvesting. If the purpose of production is the cultivation of fenugreek for green food, the plants are suitable for harvesting after treatment by "EcoFus + Siliplant”.

Table 1. Effect of complex organic-mineral fertilizers and macrosimbionts of Trigonella foenum-graecum L. plants 2017-2019

\begin{tabular}{|c|c|c|c|c|}
\hline Treatments & $\begin{array}{c}\text { Height, cm (20 days } \\
\text { after treatment) }\end{array}$ & $\begin{array}{c}\text { Height, } \mathrm{cm} \\
\text { (Harvesting) }\end{array}$ & $\begin{array}{c}\text { Yield productivity } \\
\text { (air dry mass) kg/hectare }\end{array}$ & $\begin{array}{c}\text { Number of shoots per } \\
1 \text { plant, pcs }\end{array}$ \\
\hline EcoFus + Siliplant & $42.3 \pm 3.6(107.0 \%)$ & $43.0 \pm 4.1(104.3 \%)$ & $\mathbf{3 1 2 0 . 2} \pm \mathbf{2 7 8 . 3 ( 1 2 4 . 8 \% )}$ & $5.0 \pm 0.7(131.5 \%)$ \\
\hline Rhizotorphyn & $42.6 \pm 3.8(107.8 \%)$ & $43.2 \pm 4.2(104.8 \%)$ & $2970.4 \pm 185.6(118.8 \%)$ & $4.5 \pm 0.5(118.4 \%)$ \\
\hline Control & $39.5 \pm 3.0$ & $41.2 \pm 3.5$ & $2500.6 \pm 127.9^{*}$ & $3.8 \pm 0.2 *$ \\
\hline
\end{tabular}

$*$ Values are significantly different at $\mathrm{P} \leq 0.05$.

Increasing of growing on the "EcoFus + Siliplant" and "Rhizotorphyn" types of experiment contributed to an increase in grass yield (air-dry mass) by 24.8 and $18.8 \%$, respectively, compared to the control.

Under the influence of organic-mineral fertilizers and macrosimbionts, not only the height of fenugreek plants increased, but also their bushiness by 18.4-31.5\%. This increased the yield of the above-ground part of the plants, and also led to increase the number of beans on the plants (Table 2).

Presowing inoculation of "Rhizotorphyn" increased yield productivity and quality of seeds by $32.2 \%$. Nonroot treatment with a binary mixture of "EcoFus +
Siliplant" ( $5 \mathrm{ml} / \mathrm{l}+1 \mathrm{ml} / \mathrm{l})$ increases the seed yield by $13.7 \%$ compared to control (Table 2 ).

In the analysis of table 2 a significant increase by 18.4-21.7\% weight of 1000 seeds after application of foliar treatments "EcoFus" + "Siliplant" and inoculation with "Rhizotorphyn" it is shown. After the presowing inoculation of fenugreek seeds with "Rhizotorphyn", there is a significant (at $\mathrm{P}<0.05)$ increase $(22.3 \%)$ compared with control the weight of the seeds from 1 bean.

The use of a binary mixture "EcoFus + Siliplant" increased the number of beans on the plant, but the weight and quality of seeds was influenced by presowing inoculation with "Rhizotorphyn". 
Table 2. Influence of complex application of organo-mineral fertilizers and macro-symbionts of legumes on the productivity of fenugreek, 2017-2019

\begin{tabular}{|c|c|c|c|c|}
\hline \multirow{2}{*}{ Treatments } & Seed yield & $\begin{array}{c}\text { 1000seed mass 1000, } \\
\text { gramm }\end{array}$ & $\begin{array}{c}\text { The amount of beans } \\
\text { per plant, pcs }\end{array}$ & $\begin{array}{c}\text { Amount seeds in bean, } \\
\text { pcs. }\end{array}$ \\
\cline { 2 - 5 } & Seed mass, kg/hectare & $18.4 \pm 1.92$ & $6 \pm 0.6$ & $6.7 \pm 0.84$ \\
\hline Control & $871.0 \pm 84.22$ & $22.4 \pm 2.44(121.7 \%)$ & $16 \pm 1.7$ & $7.3 \pm 1.15(108.9 \%)$ \\
\hline EcoFus + Siliplant & $996.5 \pm 91.81(113.7 \%)$ & $13 \pm 1.2$ & $\mathbf{8 . 2} \pm \mathbf{1 . 4 3 ( 1 2 2 . 3 \% )} \%$ \\
\hline Rhizotorphyn & $\mathbf{1 1 5 0 . 3} \pm \mathbf{1 1 2 . 5 4}(132.2 \%)$ & $21.8 \pm 2.23(118.4 \%)$ &
\end{tabular}

*Values are significantly different at $\mathrm{P} \leq 0.05$.

A comparative study of productivity fenugreek hay revealed the dependence of these vegetation processes on the meteorological conditions of the growing season. Thus, under cold stress (2017), fenugreek had a decrease in plant growth, bushiness and yield compared to optimal weather conditions of 2018-2019 years (Fig. 2).

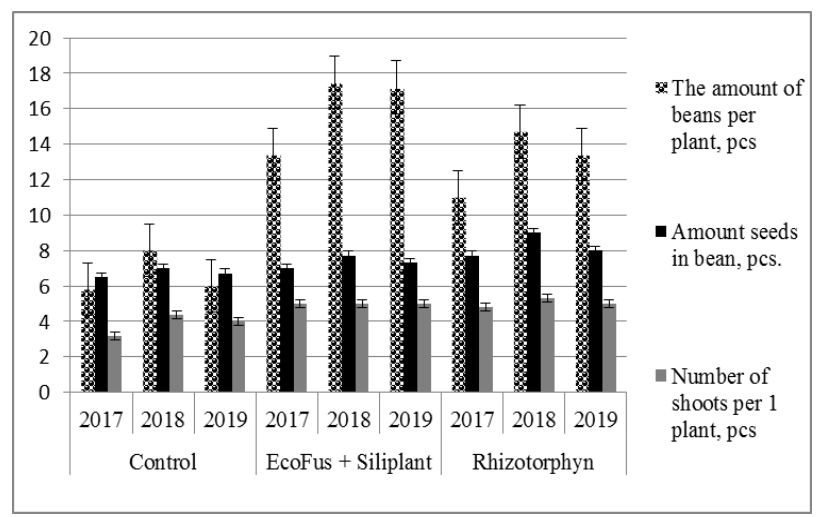

Fig. 2. Influence of foliar treatments and presowing inoculation on fenugreek crop elements depending on the conditions of the year of observation

Processing binary mixture "EcoFus + Siliplant" increased the number of beans per plant. In this case, the growing season increased to 95-110 days, the seeds did not have time for full mature. In contrast, the inoculation by "Rhizotorphyn" has proven itself in cold and wet weather conditions of 2017 and allowed obtaining high yields of seeds (Fig. 2).

It should be noted, that under adverse weather conditions in 2017, harvesting was carried out 15-20 days later than under optimal conditions for fenugreek hay. "Rhizotorphyn" under hydrothermal stress (drought conditions 2018 year) contributed to the improvement of adaptive capabilities of fenugreek to adverse weather conditions and reduced crop losses.

In the variant "EcoFus + Siliplant" was a secondary flowering of plants on the background of the warm period in August of 2018 (the average temperature was $19,8^{\circ} \mathrm{C}$ ). In this variant, uneven ripening of beans and seeds was noted.

The highest content of flavonoids was found in seeds witch had been treated by "EcoFus + Siliplant" (1.59\%). "Rhizotorphyn" increased flavonoid content by $1.09 \%$. Presowing inoculation by "Rhizotorphyn" has not effect on flavonoid content. Non root treatment by "EcoFus + Siliplant" increased flavonoid content by $45.8 \%$ (Table 3).

Presowing inoculation of Trigonella foenumgraecum L. seeds by the Rhizotorphyn have not much effect on the accumulation of flavonoids. Rizotorphyn can be used to increase seed yield and aerial mass.

Table 3. Content of flavonoids in terms of Apigenin in fenugreek seeds

\begin{tabular}{|c|c|c|c|c|c|c|}
\hline Treatments & $\mathrm{pH}$ & Optimal complexation time, min & $\lambda$ max & Flavanoid content, \% & $\mathrm{F}_{\text {fact }}$ & $\mathrm{F}$ \\
\hline EcoFus + Siliplant & 2.8 & $50-55$ & 392.68 & $1.59^{*} \pm 0.03$ & 6.025 & 5.14 \\
\hline Rhizotorphyn & 3.05 & $55-60$ & 393.61 & $1.09 \pm 0.03$ & \\
\hline Control & 4,03 & $55-60$ & 393.77 & $1.06 \pm 0.03$ & & \\
\hline
\end{tabular}

*Values are significantly different at $\mathrm{P} \leq 0.05$.

\section{Conclusion}

Non root treatment binary mixture "EcoFus + Siliplant" increased grass yield (dry mass) by $24.8 \%$ compare to control. This treatment also increases the number of beans on fenugreek plants.

Presowing inoculation increased yield of seeds by $32.2 \%$. After the presowing inoculation of fenugreek seeds with "Rhizotorphyn", there is a significant increase on $22.3 \%$ compared with control the weight of the seeds from 1 bean.

Non root treatment by binary mixture "EcoFus + Siliplant" have effect on flavonoid content in Trigonella foenum-graecum L. seeds by $45.8 \%$.

The highest flavonoid content was found in seeds subjected to foliar treatments with a binary mixture of
"EcoFus + Siliplant" (1.59\%). Seeds collected from the samples treatment by "Rhizotorphyn" slightly exceed the control variant in terms of flavonoid content $(1.09 \%)$.

\section{Acknowledgments}

The authors are grateful to Andrei Petrovich Kozhemyakov, Ph.D., the head of the Ecology Laboratory of Symbiotic and Associative Rhizobacteria of the Russian State Scientific Research Institute of Agricultural Microbiology for the provided Rizotorfin biological product.

The authors express special gratitude to Irina Evgenievna Stanishevskaya (Deputy Director for Academic Affairs, RUDN University) for phytochemical studies of Trigonella foenum-graecum L. seeds. 
The authors have no conflict of interest.

\section{References}

1. E.D. Agabalaeva, Physiological and biochemical features of the genus, Trigonella during introduction in Belarus, $\mathrm{PhD}$ dissertation thesis (Minsk, 2015)

2. T.V. Orlovskaya, V.A. Chelombit'ko, Chemistry of natural compounds, 2, 181 (2006)

3. Y. Kaya, A. Baldemir, Ü. Karaman, N. Ildız, Y. Kasko Arıcı, G. Kaçmaz, Z. Kolören, Y. Konca, Food Sci. Nutr. Feb., 7(2), 563-571 (2019) DOI: 10.1002/fsn3.849

4. C. Umesh, S. Yadav, N.Z. Baquer, Pharm. Biol., 52(2), 243-254 (2014) DOI: 10.3109/13880209.2013.826247

5. A. Alsemari, F. Alkhodairy, A. Aldakan, M. AlMohanna, E. Bahoush, Z. Shinwari, A. Alaiya, BMC Complement. and Alternat. Med., 14, 114 (2014) Retrieved from: https://doi.org/10.1186/1472-6882-14-114

6. K. El Bairi, M. Ouzir, N. Agnieszka, L. Khalki, Biomed. \& Pharmacother., 90, 479-491 (2017) Retrieved from: https://doi.org/10.1016/j.biopha.2017.03.071

7. R. Gupta, S. Nair, South Asian J. Prev. Cardiol., 3, 83-94 (1999)

8. M. Arivalagan, K.K. Gangopadhyay, G. Kumar, Indian J. of Pharmaceut. Sci., 1, 110-113 (2013) Retrieved from: https://doi.org/10.4103/0250474X.113542

9. P.R. Petit, Y D. Sauvaire, D.M. Hillaire-Buys, Steroids., 60, 674-80 (1995)

10. Z. Madar, I. Shomer, J. Agric. Food Chem., 38, 1535-39 (1990)

11. C. Broca, V. Breil, C. Cruciani-Guglielmacci, Am J. Physiol. Endocrinol. Metab., 287E, 463-71 (2004)
12. V.V. Karabaeva, G.F. Sidel'nikova, L.V. Krepkova, V.V. Bortnikova, E.V. Ferubko, Issues of biological, meducinal and pharmaceutical chemistry, 21(10), 67-71 (2018) DOI: 10.29296/25877313-2018-10-13

13. Internet resource "Climate monitor," Retrieved from: http://www.pogodaiklimat.ru/monitor

14. A.A. Hotin, ed., Conducting field experiments with medicinal crops, Medicinal plant growing. Overview information, 1, 55 (1981)

15. N.I. Sidel'nikov, N.I. Kovalev, F.M. Khazieva, Bulletin of Russian agricultural science, 3, 62-66 (2018) DOI: $10.30850 / v r s n / 2018 / 3 / 62-66$

16. N.I. Sidel'nikov, R.R. Thaganov, F.M. Khazieva, Agrochemical bulletin, 6, 57-60 (2018) DOI: 10.24411/0235-2516-2018-10063

17. A.P. Kozhemyakov, V.K. Chebotar', Biological products for agriculture, biological products in agriculture: Methodology and practice of the use of microorganisms in crop production and fodder production 18-54 (RASHN, Moscow, 2005)

18. I.A. Tihonovich, A.Yu. Borisov, A.G. Vasil'chikov, V.A. Zhukov, A.P. Kozhemyakov, T.S. Naumkina, V.K. Chebotar', O.Yu. Shtark, V.V. Yahno, Legumes and cereals, 3, 11-17 (2012)

19. R. Badar, U. Rashid, A. Siddiqa, M. Kaleem, H. Khurshid, S. Sadaf Altaf, H. Khalid, W. Mushtaque, N. Yaseen, J. of Pharmacogn. and Phytochem., 5(2), 288-290 (2016)

20. V.A. Tutelyan, ed., Guidelines for quality control and safety of dietary supplements 127-131 (Federal center of Gossanepidnadzor of the Ministry of health of Russia, Modcow, 2004)

21. I.A. Samylina, T.A. Sokol'skaya, V.N. Davydova, Issues of biological, meducinal and pharmaceutical chemistry, 5, 4-5 (2011)

22. P. Zimmet, J. Shaw, G. Alberti, Diabet. Med., 20(9), 693-702 (2003) 